\title{
CONTRIBUIÇÕES DO MARKETING SOCIAL NA FORMAÇÃO DO ADMINISTRADOR
}

CONTRIBUTIONS OF SOCIAL MARKETING IN ADMINISTRATOR TRAINING

Recebido em: 13/11/2018 • Aprovado em: 25/02/2019

Avaliado pelo sistema double blind review

Editor Científico: Edson Sadao Iizuka DOI 10.13058/raep.2019.v20n2.1328

\section{STEPHANIE INGRID SOUZABARBOZA stephanieisb@gmail.com WESLEY FERREIRA DA SILVA}

Universidade Federal da Paraíba

\begin{abstract}
RESUMO
A formação dos estudantes de administração no Brasil é centrada quase exclusivamente em aspectos gerenciais do marketing e, por conta disso, os profissionais graduados parecem incapazes de lidar com a complexidade das aplicações do conhecimento de marketing. Dessa forma, a presente pesquisa buscou incorporar, de forma experimental, os conteúdos de marketing social dentro da disciplina de administração de marketing na graduação em administração, a fim de analisar suas contribuições na formação dos alunos. Para isso, a pesquisa ocorreu em duas etapas distintas, de modo que, primeiramente, foi realizado um seminário de marketing social dentro da disciplina de administração de marketing; em seguida, foram realizados grupos focais a fim de se obter a comparação entre as dimensões: conceituação deficiente de mercado, desconexão entre marketing e sociedade, e visão acrítica, propostas por Bernadinelli e Sauberbron (2017) para a formação do administrador. Ao fim da pesquisa, concluiu-se que o ensino do marketing social proporcionou aos alunos uma melhor compreensão do marketing enquanto ciência de ampla atuação, diminuindo significativamente a separação entre marketing e sociedade e os papéis dos stakeholders que compõem o mercado.
\end{abstract}

Palavras-Chave: Marketing Social, Educação em Marketing, Administração.

\begin{abstract}
The training of management students in Brazil is centered on managerial aspects of marketing and, because of this, graduates seem unable to deal with the complexity of the applications of marketing knowledge. Thus, the present research sought to incorporate experimentally the social marketing contents within the discipline of marketing administration in the undergraduate degree in administration, in order to analyze their contributions in the formation of the students. For this, the research took place in two distinct stages: first, a social marketing seminar was conducted within the discipline of marketing administration; then, focus groups were carried out in order to obtain a comparison between the dimensions: deficient market conceptualization, disconnection between marketing and society, and uncritical vision, proposed by Bernadinelli and Sauberbron (2017) for the training of the administrator. At the end of the research, it was concluded that social marketing teaching provided students with a better understanding of marketing as a broad-based science, significantly reducing the separation between marketing and society and the stakeholder roles that make up the market. Keywords: Social Marketing, Marketing Education, Management.
\end{abstract}




\section{INTRODUÇÃO}

O ensino de administração no Brasil no nível de graduação teve um crescimento expressivo nos últimos 15 anos, resultante de um aumento intensivo na quantidade de cursos e no número de alunos matriculados. Segundo dados do Censo da Educação Superior (2018), o curso de administração ocupa o terceiro lugar no ranking dos cursos mais procurados no Brasil, representando aproximadamente 700 mil das matrículas no ensino superior em 2017. Todavia, esse crescimento não foi necessariamente acompanhado pela melhoria da qualidade da formação do administrador (OLIVEIRA et al., 2015). Neste cenário, torna-se compreensível o fato da comunidade científica ter demonstrado uma crescente preocupação com os aspectos educacionais da formação de administradores no Brasil, produzindo uma grande quantidade de trabalhos acerca do tema e refletindo seu interesse na área (SCHMITZ et al., 2015; RODRIGUES; MATIAS, 2016; URIAS; AZZEREDO, 2017; MULLER; SCHUSTER; ZONATTO, 2017).

Naturalmente, o ensino da disciplina de marketing em cursos de administração também tem despertado o interesse de pesquisadores brasileiros (BERNADINELLI; SAUBERBRON, 2017), que, de forma geral, constataram uma orientação generalista no ensino do marketing no país, com foco excessivo nas relações entre as empresas produtoras de bens e serviços e os consumidores. Essa orientação mais tradicional faz com que as disciplinas de marketing nos cursos de administração se caracterizem por meio de uma abordagem limitada, pouco reflexiva e passiva frente aos fatos e mudanças sociais, ao passo em que desconsidera as relações entre o marketing e a sociedade (LEE; GREENLEY, 2010). Com efeito, de acordo com Bernadinelli e Sauberbron (2017), as principais deficiências no ensino em marketing nos cursos de administração no Brasil são caracterizadas pelo fato de haver um foco excessivo na área do micromarketing, sendo negligenciado o estudo do macromarketing e sua importância na formação do administrador.

Diante disso, é importante que sejam realizados esforços para aprimorar o ensino da disciplina, ao introduzir conteúdos que forneçam novas perspectivas aos alunos, sobretudo as que priorizem o entendimento 
do marketing no nível macroeconômico (BERNARDINELLI; SAUERBRONN, 2017). Para o ensino de marketing a partir de um viés que favoreça a percepção dos alunos em torno das relações entre o marketing e a sociedade, é importante que sejam realizados esforços que evidenciem a dinamicidade da aplicação das ferramentas de marketing assim como o entendimento de que a troca pode ser operacionalizada pelos mais diversos agentes de mercado.

Nesse ímpeto, é possível afirmar que a inclusão do conteúdo de marketing social pode contribuir para a melhoria da formação dos alunos de administração no Brasil, uma vez que busca desenvolver os conceitos de marketing com outras abordagens, no sentido de influenciar comportamentos que beneficiem indivíduos e comunidades na promoção do bem-estar social (DIBB, 2014). No cenário internacional, é possível identificar tentativas recentes de inserir o estudo do marketing social nas disciplinas dos cursos de negócios (RADFORD; HUNT; ANDRUS, 2015; TEKLEHAIMANOT et al., 2017), mas no Brasil as tentativas de objetivo semelhante ainda estão em fase embrionária, não havendo ainda estudos relevantes nesta área específica.

Nesse sentido, faz-se necessário empreender uma análise sobre as contribuições do marketing social para o ensino de marketing e, principalmente, para a formação dos administradores. Dito isso, a proposta desse artigo é analisar as contribuições do marketing social para a formação dos administradores a partir da inserção desse conteúdo na disciplina de administração de marketing de uma Instituição de Ensino Superior.

Para o desenvolvimento dessa pesquisa, é apresentada a revisão da literatura com uma breve exposição sobre o ensino de marketing e as dimensões da formação do administrador, além de uma discussão sobre marketing social. Em seguida, são exibidos os procedimentos metodológicos adotados para análise experimental da influência do conteúdo de marketing social na visão dos estudantes de administração, para a qual foi realizada uma ação de formação baseada em metodologias ativas e operacionalizados grupos focais entre os participantes do seminário e um grupo de controle. Por fim, são apresentados os resultados observados na pesquisa e as considerações finais. 


\section{O ENSINO DE MARKETING E AS DIMENSÕES DA FORMAÇÃO DO ADMINISTRADOR}

Segundo Martins (1989), o ensino e a pesquisa de administração e de marketing no Brasil têm início no ano de 1954, com a criação da Escola de Administração de Empresas da Fundação Getúlio Vargas (EAESP/ FGV), que tinha como objetivo formar técnicos de nível superior em administração, podendo ser considerada como introdutória do pensamento de marketing no Brasil, uma vez que formou uma associação com a Michigan States University (COSTA; VIEIRA, 2007). Outras duas importantes iniciativas de introdução do ensino de marketing no país se sucederam na forma da criação da Faculdade de Economia e Administração da Universidade de São Paulo (FEA/USP), em 1989 (MARTINS, 1989), e da Escola Superior de Propaganda, posteriormente denominada Escola Superior de Marketing e Propaganda (ESPM).

Neste mesmo período, professores brasileiros foram aos Estados Unidos, na busca por desenvolver conhecimentos específicos de marketing. Apesar destes esforços, não houve uma adaptação do modelo norte-americano à realidade brasileira, apenas a importação da grade curricular para os cursos de administração (BOAVENTURA et al., 2018).

Por outro lado, há uma crescente preocupação com a qualidade da formação de administradores no Brasil (LOURENÇO; TONELLI; MAFRA, 2012), sendo cada vez mais frequentes as discussões a respeito do ensino de variadas disciplinas que pertencem à grade curricular básica da graduação em administração, tendo sido produzida uma expressiva quantidade de trabalhos que refletem o interesse na temática (RODRIGUES; MATIAS, 2016; URIAS; AZZEREDO, 2017; MULLER; SCHUSTER; ZONATTO, 2017).

É possível observar, por meio da evolução do pensamento de marketing ao longo do tempo, mudanças significativas no discurso acerca do conceito e da finalidade de marketing, bem como sobre a mudança de foco no produto para o foco nas relações de trocas e suas implicações (BARBOZA, 2014). Porém, no nível de graduação, escolas como a de marketing social são negligenciadas no conteúdo das disciplinas de marketing, o que impac- 
ta no entendimento da amplitude de aplicação desse conteúdo na formação dos graduandos em administração.

Em pesquisa recente, Bernadinelli e Sauberbron (2017) identificaram, com base na exploração de experiências docentes, claras lacunas com relação à formação mercadológica do administrador no Brasil, sendo elas: pouca compreensão a respeito do conceito de mercado, desconexão entre o conhecimento da disciplina e a sociedade, e falta de visão crítica acerca das atividades de marketing. Os autores constataram que a formação em marketing do administrador é considerada insuficiente e a abordagem micro e gerencial adotada para a graduação é vista como reducionista.

Em grande parte, isso ocorre porque a disciplina de marketing não promove aprofundamento da compreensão do aluno a respeito do conceito de mercado. Além disso, Bernadinelli e Sauberbron (2017) apontaram que o conteúdo lecionado em marketing nos cursos de administração promove $\mathrm{o}$ distanciamento de marketing da sociedade. $\mathrm{O}$ afastamento entre marketing e sociedade no conteúdo da disciplina é apontado por Tamilia e Veillex (2007) e por Flleming et al. (2015) como uma característica dos cursos de graduação contemporâneos, focados em temas da administração de marketing e do comportamento do consumidor, relegando a sociedade a mero fator "externo".

A terceira lacuna no ensino do marketing em cursos de graduação de administração identificada por Bernadinelli e Sauberbron (2017), diz respeito a uma visão acrítica no currículo da disciplina. Este tópico está relacionado tanto à replicação de conceitos limitados quanto à falta de um conteúdo mais próximo da realidade brasileira. Os autores apontaram para a necessidade de se complementar o conteúdo correntemente ensinado com uma perspectiva mais ampla a respeito das implicações das atividades de marketing para fora da organização e, consequentemente, proporcionar ao aluno uma visão crítica (BERNADINELLI; SAUBERBRON, 2017). Estes pontos de vista vão ao encontro da posição defendida por Vasconcelos, Costa e Carvalho (2016), que afirmam que restringir o marketing apenas à visão do micromarketing limita também a formação crítica e reflexiva dos estudantes de administração. 
É possível dizer, portanto, que dado o foco demasiadamente empresarial da disciplina, os alunos de administração não estão desenvolvendo a capacidade de resolver problemas sociais que envolvam diversos agentes interessados ou problemas relativos a trocas complexas. Neste cenário, é evidente a necessidade de se discutir novas propostas para o ensino de marketing nos cursos de administração, de forma a suprir as lacunas na formação dos graduandos. 


\section{MARKETING SOCIAL}

Introdutoriamente, Kotler e Zaltman (1971) apresentaram o termo "marketing social" para definir a utilização das ferramentas de marketing para a promoção da mudança social (KOTLER, 2013). Para este estudo foi adotada uma definição baseada em um consenso, endossado em 2013 pela Associação Internacional de Marketing Social (ISMA), pela Associação Europeia de Marketing Social (ESMA) e pela Associação Australiana de Marketing Social (AASM), cujo entendimento é que marketing social desenvolve e integra os conceitos de marketing com outras abordagens teóricas para influenciar comportamentos que beneficiem indivíduos e comunidades. Em suma, a premissa norteadora de marketing social é a adoção de princípios éticos que integrem pesquisas, práticas, teorias, audiências e parcerias com o fim de informar e promover a mudança social equitativa e sustentável (CARVALHO; MAZZON, 2014).

De maneira geral, o marketing social busca alcançar seus objetivos por meio da promoção das mudanças de comportamento; contudo, seus resultados não são medidos por número de vendas, reconhecimento de marca ou participação de mercado, mas por meio de resultados que analisam o bem-estar individual e societal (DIBB, 2014). As ideias do marketing social podem ser aplicadas a uma grande variedade de problemas e populações; em diferentes escopos de atuação - global, nacional, regional e até mesmo individual, utilizando os princípios de marketing para possibilitar transformações sociais sustentáveis (SAUNDERS; BARRINGTON; SRIDHARAN, 2015).

Adotando a perspectiva do modelo ecológico defendida por Wood (2016), estudiosos reforçam que as ações de marketing social dependem da relação entre três níveis dentro de um mesmo ecossistema. O nível micro, denominado downstream, foca a análise de marketing social em indivíduos com comportamentos problemáticos. O nível meso ou midstream inclui os agentes organizacionais, como organizações não lucrativas, organizações de marketing social e grupos comunitários, que podem se conectar direta e indiretamente para servir uns aos outros e co-criar valor para promoção 
da mudança social. O nível final no ecossistema é o macro, que inclui atores como legisladores, governo e o mercado, sendo referenciado também como upstream na literatura do marketing social (BEIRÃO et al., 2017).

Para Niblett (2005), o nível upstream expressa como são alteradas as políticas, leis, regulações e ambientes físicos que podem marginalizar ou tornar inútil os esforços em conseguir que os indivíduos mudem seu comportamento diante das barreiras e ofertas impostas comercialmente ou ambientalmente. French, Bennett e Mulcahy (2017) explicam que atividades e intervenções upstream focam na formulação de políticas, na alocação de recursos, na regulação e influência na estratégia dos agentes causadores e determinantes dos problemas sociais. Além disso, é possível notar uma tendência de movimentação do marketing social voltado ao midstream e upstream, sendo dada cada vez menos importância às ações em nível downstream (DIBB, 2014; BRENNAN; PARKER, 2014).

Em verdade, o paradigma tradicional do gerenciamento de marketing adotado pelo marketing social se traduz em uma abordagem downstream, focada em mudar o comportamento de pessoas por meio de decisões no nível individual (GORDON; GURRUERI, 2014; MAIO et al., 2007). Todavia, os críticos argumentam que o foco individual privilegia um modelo de decisão racional, próprio da perspectiva de micromarketing, negligenciando questões de agência e fatores contextuais, os quais são fortes determinantes do comportamento dos indivíduos (GORDON; GURRIERI, 2014). Dessa forma, é possível notar uma reorientação em direção ao marketing social upstream e midstream, ao partir do contexto da mudança comportamental utilizando combinações de medidas estruturais, legislação, abordagem de comunidades e educação (DIBB, 2014; FRENCH; BENNETT; MULCAHY, 2017; KENNEDY; KEMPER; PARSONS, 2018).

Essa mudança vem sendo acompanhada pela necessidade de abordagens mais estratégicas para delinear intervenções. Dibb (2014) afirma que as intervenções necessárias para a resolução de problemas sociais complexos devem ser holísticas e com múltiplas camadas, fazendo-se necessário integrar o upstream, midstream e downstream, e envolver diferentes números de agentes. Nessa nova realidade, é preciso que os praticantes de marke- 
ting social se tornem adeptos a trabalharem em conjunto com os agentes envolvidos em entregar intervenções upstream e midstream, incluindo políticos, educadores, empresas privadas, organizações comunitárias e a mídia (HAMBY; PIERCE; BRINBERG, 2016).

Dessa forma, a discussão do presente trabalho se baseia na capacidade de o conteúdo de marketing social ser complementar às lacunas da formação em administração. Isso porque, tal conteúdo apresenta aos alunos uma visão ampla do marketing ao propor, prioritariamente, a resolução de problemas sociais complexos. 


\section{PROCEDIMENTOS METODOLÓGICOS}

A presente pesquisa foi conduzida em duas etapas complementares. $\mathrm{Na}$ primeira etapa, realizou-se um seminário que teve por objetivo fornecer uma formação básica sobre o conteúdo de marketing social, por meio de aulas expositivas e do uso de metodologias ativas de ensino, ministradas aos alunos da disciplina de Administração de Marketing I da graduação em administração de uma Instituição de Ensino Superior do Nordeste. O seminário foi estruturado para expor a teoria do marketing social, engajando os alunos em atividades práticas, de forma a desenvolver uma visão ampla sobre a aplicação do marketing social na tentativa de solucionar problemas sociais complexos e reais. Para isto, foram definidos cinco encontros que totalizaram 10 horas/aula.

Os dois primeiros encontros foram compostos de aulas expositivas, realizadas em sala de aula com a turma de Administração de Marketing I. A primeira aula teve por objetivo introduzir os discentes às teorias do marketing social, apresentando seu conceito (AASM, ISMA e ESMA, 2013), e sua evolução histórica (DIBB, 2014). Na segunda aula, por sua vez, foi apresentada a abordagem do modelo ecológico de marketing social (BEIRÃO et al., 2017).

No terceiro momento, tiveram início as atividades baseadas nas metodologias ativas de ensino, com base na análise do filme Obrigado por Fumar, de 2006. O objetivo da análise filmica foi incentivar o pensamento crítico e a reflexão acerca dos comportamentos de consumo, uma vez que o filme retrata como o marketing, com ênfase nas relações públicas, tem o poder de influenciar comportamentos sociais coletivos a partir do contexto da indústria tabagista. A análise desse filme permitiu fornecer aos alunos uma visão apropriada da abordagem upstream no marketing social, pois permite visualizar as estratégias utilizadas pelos agentes sociais em um nível macroeconômico, bem como seu impacto na vida de incontáveis indivíduos (KENNEDY; KEMPER; PARSONS, 2018). Dessa forma, foi possível para os alunos perceberem como os agentes causadores e determinantes dos problemas sociais (legisladores, organizações não governamen- 
tais, grandes corporações, dentre outros) podem influenciar direta ou indiretamente o comportamento dos indivíduos de uma sociedade, podendo ser tanto a causa dos problemas sociais quanto a sua solução (KENNEDY; KEMPER; PARSONS, 2018).

O quarto encontro foi realizado de forma participativa e colaborativa, tendo sido realizadas discussões em grupo em torno de um painel de notícias. Os alunos foram divididos em grupos de cinco integrantes cada, para os quais foram distribuídas notícias publicadas em mídias digitais que ilustrassem de alguma forma ações de marketing social desenvolvidas por atores midstream, como agentes comunitários e organizações sociais. Após a leitura e discussão interna do grupo sobre o assunto, foi solicitado que cada um deles compartilhasse com os demais um resumo da situação descrita na notícia, bem como suas considerações acerca da efetividade e relevância das ações descritas. Em seguida, todos os demais grupos prosseguiram debatendo sobre todas as notícias. Essa atividade propôs que os alunos se colocassem na posição de gestor de marketing social, na medida em que refletiam sobre as intervenções promovidas na mudança de comportamento de comunidades, famílias, focando seus esforços nos comportamentos coletivos (WOOD, 2016; FRENCH; BENNETT; MULCAHY, 2017).

Por fim, para alcançar a proposta do seminário, no último encontro foi realizada a aplicação de um caso para ensino. O caso escolhido foi "Não Zere a Quilometragem, meu Jovem! Marketing Social para Educação no Trânsito" (MORAES; LACERDA, 2016), com intuito de trazer para a realidade do curso de administração a discussão sobre o indivíduo como agente executor das políticas públicas e de regulação no combate à violência de trânsito. O objetivo principal do caso foi propor uma discussão sobre a conscientização de jovens no trânsito, convidando os alunos a proporem possíveis soluções aos problemas apresentados. A atividade permitiu abordar os problemas descritos pela ótica downstream, contextualizando a teoria por meio de sua aplicação em um caso prático pertinente à realidade local, bem como incitar o desenvolvimento do pensamento de marketing social e suas aplicações práticas na mudança de comportamento de indivíduos (FRENCH; RUSSELL-BENNETT; MULCAHY, 2017). 
$\mathrm{Na}$ segunda etapa da pesquisa foram realizados três grupos focais a fim de avaliar, de forma comparativa, o desempenho de cada um dos grupos com relação às lacunas identificadas no ensino de marketing e na formação do administrador. Para se alcançar os objetivos do presente trabalho, a ferramenta de coleta de dados de grupo focal foi utilizada por permitir ao pesquisador direcionar as discussões e as reflexões dos participantes sobre os conceitos, impressões e concepções de determinado tema.

A construção do roteiro para os grupos focais se baseou em lacunas na formação dos administradores identificadas por Bernadinelli e Sauerbronn (2017) no que diz respeito aos conhecimentos de marketing, a saber, pouca compreensão a respeito do conceito de mercado; desconexão entre o conhecimento teórico da disciplina e sua aplicação social na prática; e falta de visão crítica acerca das atividades de marketing; e crise de relevância quanto à importância do marketing para a sociedade. Dessa forma, cada pergunta do roteiro foi elaborada de modo a iniciar uma discussão sobre cada um dos aspectos que compõem as lacunas, objetivando incentivar os alunos a discorrerem sobre os temas. Com isso, foi possível identificar a construção do pensamento coletivo, a fim de descobrir se a exposição dos grupos aos conceitos de marketing social contribuiu para suprir as demandas apontadas Bernadinelli e Sauberbron (2017) no desenvolvimento do conhecimento de marketing.

Para tanto, foram realizados três grupos focais distintos. O primeiro grupo, denominado nesta pesquisa de grupo de controle, analisados sob a sigla GC, foi composto por alunos da graduação de administração do período noturno que não participaram do seminário de marketing social. Os participantes deste grupo têm como característica terem cursado a disciplina de Administração de Marketing I, além de cursarem outras disciplinas relacionadas ao conteúdo de marketing. A aplicação desse grupo ocorreu em maio de 2018 e contou com a participação de dez alunos, com duração total de cinquenta e cinco minutos e dezoito segundos (00h:55m:00s), registrados em áudio; a transcrição resultou em dezenove (19) laudas com fonte Times New Roman, tamanho 12 e espaçamento simples. 
Complementarmente, foram realizados outros dois grupos focais, denominados neste trabalho de Grupo 2 e Grupo 3 e analisados sob a sigla GE, com os alunos da graduação em administração que participaram do seminário de marketing social no mês de junho de 2018. Os alunos destes dois grupos cursaram a disciplina de Administração de Marketing I, sendo contabilizada a participação de quatorze alunos, sete no grupo 2 e sete no grupo 3. O grupo 2 teve duração de cinquenta e dois minutos (00:52:00), enquanto o grupo 3 teve duração de cinquenta minutos e quarenta e sete segundos (00:50:47), os quais, após a transcrição do registro em áudio, geraram, respectivamente, dezessete e quinze laudas com fonte Times New Roman, tamanho 12 e espaçamento simples.

Para análise dos dados, foi utilizado o método da análise de conteúdo, pois busca obter, por meio de procedimentos sistemáticos e objetivos de descrição dos conteúdos das mensagens, indicadores que permitam a inferência dos conhecimentos relativos às condições de produção destas mensagens (ROSSI; SERRALVO; JOÃO, 2014). Para o presente trabalho, utilizou-se da técnica de análise por categorias temáticas, que consiste na realização de operações de desmembramento do texto em unidades e categorias segundo reagrupamento analógicos conforme os temas que emergem do texto, ao identificar similaridade entre os elementos (BARDIN, 2011). Emergiram como categorias de análise: a relevância do marketing na formação do administrador, conceituação de mercado e agentes de mercado, visão acrítica, e conexão entre marketing e sociedade. Os resultados da análise dessas categorias estão expostos no item subsequente. 


\section{ANÁLISE DOS RESULTADOS}

\section{Relevância do Marketing na Formação do Administrador}

Nesse item objetivou entender o posicionamento dos alunos acerca da relevância do marketing na formação da administração, a partir dos resultados dos grupos focais. Desse modo, em primeira análise, os alunos do grupo de controle acreditam que o conteúdo de marketing é imprescindível para o profissional de administração, pois se configura como um conjunto de ferramentas necessárias para que a organização alcance o sucesso dentro do seu mercado. Sgundo os entrevistados, essas ferramentas variam dentro das atividades de marketing, posto que enfatizaram o seu uso para conhecer o público-alvo e suas necessidades. Esse entendimento pode ser observado no discurso de um dos participantes do grupo de controle.

Eu vejo como uma matéria muito importante para qualquer gestor, para o administrador, porque a disciplina de marketing, você vê muitas ferramentas para fazer análise do consumidor, análise dos concorrentes, e são ferramentas úteis em qualquer mercado (GC5).

Para o grupo de controle, o conteúdo do marketing apresentado na graduação tem sua importância pelo fato de possibilitar a criação de valor para os clientes da organização, satisfazendo-o por meio de produtos ou serviços que atendam seus desejos e necessidades. Kotler (2013) afirma que "normalmente, o marketing é visto como a tarefa de criar, promover e fornecer bens e serviços a clientes, sejam estas pessoas físicas ou jurídicas, mas essa é uma visão demasiadamente simplista” (p. 27).

Esse entendimento do marketing como ferramenta organizacional tem origem no fato de que os cursos de administração, em nível de graduação, focam quase que exclusivamente no estudo do chamado micromarketing, que é o estudo de atividades de marketing de unidades individuais, como as organizações empresariais e as sem fim lucrativo (HUNT, 1983). Os alunos também identificaram o marketing como sendo importante nas decisões estratégicas da organização, sendo apontado como a área mais importante dentro da empresa: 
O marketing visto geralmente como estratégia, o marketing estratégico, ele é muito importante. E é ele que guia as outras áreas. Porque o marketing estratégico ajuda a enxergar a demanda (GC10).

Essa visão do marketing enquanto estratégia parte da perspectiva organizacional com foco no cliente, uma vez que os processos de marketing são os responsáveis por definir os produtos e serviços e as condições nas quais eles irão operar dentro dos mercados (KOTLER, 2013). Apesar de expandir a importância do marketing dentro da organização, essa visão continua restrita à empresa, o que, segundo Berardinelli e Sauerbronn (2017), causa uma lacuna na formação do profissional, uma vez que não o capacita para resolver problemas complexos, que envolvam vários agentes dentro do mercado.

Diferentemente da perspectiva presente no grupo de controle, os alunos dos grupos 2 e 3 apresentaram um entendimento de marketing que extrapola a noção de marketing empresarial, considerando o estudo do marketing como o estudo das trocas e de suas implicações, conforme é observado em alguns relatos.

O marketing, ele vai servir para entender melhor as relações de troca numa organização com a sociedade (GE5).

Eu acho que assim como outras disciplinas, ele vai dar uma visão melhor a você de como funciona o mercado. Como entender melhor o mercado, e acho que partindo desse princípio aí, conseguir ver a troca de uma maneira mais eficiente. $E$ conseguir enxergar que tudo ali tem uma troca (GE8).

Dessa forma, percebe-que os alunos dos grupos que participaram do seminário de marketing social apresentam uma compreensão mais ampla do marketing e sua importância. Essa compreensão expande o campo de trabalho do administrador, no que diz respeito ao conteúdo aprendido na disciplina de marketing, pois permite que os egressos consigam aplicar os conhecimentos em situações mais diversificadas, uma vez que a ciência do marketing como estudo das trocas deve ser capaz de explicar o fenômeno da troca em qualquer manifestação e sob qualquer ponto de vista (HILL; MARTIN, 2014). 


\section{Conceituação e entendimento de mercado}

Este tópico analisa a percepção dos alunos quanto ao mercado e aos agentes de mercado, sendo mencionada por Suaerbronn e Bernadinelli (2017) como uma das grandes lacunas com relação à formação mercadológica do administrador no Brasil. Com efeito, Fligstein e Calder (2002) definem mercado como sendo composto de indivíduos e organizações que estão interessados em adquirir produtos ou serviços para obter benefícios que irão satisfazer uma necessidade ou desejo específico, e que detêm os recursos necessários para se engajar em tal transação. Ou seja, o mercado não é um local físico, mas sim todo um arranjo pelo qual ofertantes e demandantes se encontram para realizar uma transação (FLIGSTEIN; CALDER, 2002). Os participantes dos três grupos forneceram definições para o mercado que estão de acordo com a teoria de marketing, como exposto nas falas:

O mercado é ambiente em que a empresa, o consumidor, o governo a concorrência, todos se encontram, e é ali que a troca do produto ou serviço, o custo e o valor percebido pelo cliente, eu acho que é o mercado é isso, essas trocas onde esses agentes estão envolvidos (GC5).

Ele é composto de, na minha concepção, de elementos que forneçam determinada coisa em detrimento de outra, como um papel moeda, por exemplo, como objeto de transação. (...) basicamente, é um ambiente onde ocorrem as relações de trocas entre os agentes (GE5).

É o espaço onde clientes, vendedores, fornecedores, o próprio estado, cobrando os impostos, todas as pessoas que querem pegar uma fatia ou se beneficiar de alguma forma daquela atividade, daquele mercado (GE8).

Para Bernardinelli e Sauerbronn (2017), a capacidade de conceituar o mercado é de suma importância para o aluno de administração, mais importante até do que conhecer as estratégias de marketing de empresas, pois "não faz o menor sentido você estudar um universo de estratégias desconsiderando toda a constituição de mercado, todas as práticas de mercado, todos os agentes de mercado" (2017, p. 574). Na literatura, são considerados agentes de mercado toda entidade, organização ou grupos de indivíduos que exercem influência dentro do mercado, seja por meio de 
atividades de trocas ou de regulamentação (FLIGSTEIN; CALDER, 2002). No grupo de controle, os alunos conseguiram identificar como agentes de mercado as empresas, o estado e a sociedade, porém é perceptível que o reconhecimento deste último enquanto agente de mercado limita-se aos consumidores, cujo papel dentro do mercado é o de consumir os produtos e serviços ofertados pelos demais agentes, como demonstrado pelos discursos de dois participantes.

Dentro do mercado vão existir os agentes ofertantes e os agentes demandantes. Os demandantes são os compradores, no caso, os consumidores e os ofertantes seriam as organizações, as empresas (GC2).

O cliente é o agente demandante, o papel dele é consumir né? (GC7)

Essa perspectiva é limitada, uma vez que impede os profissionais de administração de compreenderem a sociedade como um agente complexo, cujos desejos e necessidades nem sempre podem ser supridos pelo mercado. Ao discorrer sobre a função do Estado, os alunos do grupo de controle afirmaram que sua função como agente de mercado é exercer o papel regulador, como pode ser observado:

O Estado age na própria regulamentação, muitas vezes de forma até meio estúpida, definir o que você pode vender, como você deve vender, para quem você deve vender. Tem cidades do Brasil que você não pode vender carne na segunda feira por exemplo. Então esse tipo de regulamentação influencia o mercado (GC5).

(...) O Estado age como regulador da concorrência, para estar de acordo com as diretrizes estabelecidas (GC9).

Coelho (2014) afirma que todos os mercados, sem exceção, estão sempre sujeitos a alguma forma de regulação e requerem sempre regras e princípios para funcionar. Assim, caberia ao estado apenas assegurar o bom funcionamento do mercado, impedindo que os produtores se organizem em cartéis, ou o monopólio de algum setor, distorcendo os preços e beneficiando apenas a si mesmos. Dessa forma, o estado estaria beneficiando de forma direta e indireta todos os outros agentes, inclusive a sociedade. 
Se só uma empresa existisse o mercado seria refém, as pessoas teriam as demandas supridas por uma só empresa, não teria como conseguir um preço melhor, uma qualidade melhor (GC5).

Ao serem questionados sobre o papel das empresas enquanto agentes de mercado, os alunos do grupo de controle apresentaram a seguinte visão:

A obrigação da empresa é primeiramente conhecer os consumidores de determinado mercado, formatando seus produtos de acordo com as suas preferências, gerando valor (GC8)

Kotler e Armstrong (2014) acreditam que o marketing ocorre quando as pessoas decidem satisfazer suas necessidades e desejos por meio das trocas. Dessa forma, é possível perceber que a percepção do grupo de controle está alinhada com aquilo encontrado na teoria, porém os participantes desse grupo não conseguiram expandir a perspectiva para além das atividades comerciais que a empresa realiza.

Ao analisar os discursos dos grupos focais 2 e 3, é possível perceber que os participantes compreendem a sociedade como um agente de mercado ativo, cuja influência é exercida não só na demanda de produtos e serviços, mas também influenciando os outros agentes a se adequarem às suas normas morais, agindo através do poder econômico, social, institucional e também exercendo pressão no Estado. O relato reforça tal entendimento:

A população em si influencia para que leis sejam criadas, então a população pode ver isso juntamente com o estado para criar leis que digam que não pode ser vendido determinado produto que faça mal ao meio ambiente por exemplo (GE11).

Embora a regulamentação seja um papel importante, e até mesmo exclusivo do Estado, ele não é o único. Os alunos dos grupos focais 2 e 3 conseguiram identificar outros papéis exercidos por esse agente dentro do mercado, conforme exposto em um dos discursos. 
Estado tem um papel de regulamentar, recolher os impostos, de certa forma, com os impostos que arrecada, deveria investir infraestrutura, segurança, tudo que possa melhorar o mercado como um todo (GE11).

Por essa percepção, o Estado deixa de ser visto apenas como um regulamentador externo ao mercado, e passa a ser entendido como um agente ativo responsável também por recolher os impostos e investir, no intuito de aprimorar os processos de troca entre os demais agentes. Nesse mesmo sentido, e diferentemente do grupo de controle, os alunos dos grupos 2 e 3 demonstraram uma compressão mais ampla acerca do papel da empresa dentro do mercado.

A gente sabe que a empresa tem que ter a responsabilidade social, é claro que ela deve vender, mas ela também tem que pensar na sociedade. Porque como eu vou vender um produ to que está impactando a sociedade, o meio ambiente, agora no presente, sabendo que no futuro ele pode prejudicar? Eu como administradora, com esse conhecimento de marketing tenho que pensar como eu posso melhorar essas questões (GE11).

A compreensão sobre o papel da empresa, portanto, supera a atuação regulatória das atividades comerciais baseadas em oferta e demanda, ao posiciona-la não como uma entidade alheia à sociedade, mas que faz preservar e ser sustentável economicamente, socialmente e ambientalmente. Vale salientar que os grupos 2 e 3 se colocaram sempre favoráveis à lucratividade, desde que alcançada de uma forma não prejudicial ao demais agentes de mercado:

Eu lembro que se falou que o papel social da empresa é o lucro, por que com o lucro ele vai poder pagar os empregados, os impostos, então eu acredito que não devemos ter aquele capitalismo feroz, de só o lucro por cima do lucro, mas que deve sim existir o lucro. (GE8)

Eu vejo essa questão do lucro, sou a favor do lucro, mas ai é estudar formas de se ter impactos positivos na sociedade. (GE9).

Os grupos 2 e 3 identificaram um agente de mercado que não foi citado durante a entrevista com o grupo de controle: as organizações não 
governamentais. Bromley e Meyer (2018) explicam que as ONG's, principalmente aquelas que não visam o lucro, surgem como consequência da insatisfação de determinados grupos de indivíduos que não tiveram suas demandas satisfeitas ou que foram negligenciadas pelos demais agentes de mercado. Um aluno destacou como as organizações não-governamentais podem agir dentro do mercado.

Para mim as ONGs servem para suprir uma lacuna que o governo não consegue alcançar. Porque nem tudo o governo vai poder suprir. As ONG's nesse caso vão existir para suprir as necessidades da população (GE1).

Ao introduzirem as organizações não-governamentais em seu discurso, os alunos demonstram um certo nível de entendimento sobre as trocas complexas, que são aquelas que possuem mais de dois agentes envolvidos. No exemplo citado, é possível colocar o Estado atuando em nível macro, e as ONGs como agentes que buscam suprir as necessidades da população, agindo no nível meso, ao mesmo tempo em que têm suas necessidades supridas por outros agentes, incluindo o governo, como é o caso dos financiamentos para projetos sociais.

\section{Relação marketing e sociedade}

Além de uma compreensão estreita a respeito do conceito de mercado, Sauerbron e Bernadinelli (2017) também apontaram que o conteúdo de marketing nos cursos de administração é distante da sociedade. Essa lacuna ocorre pelo fato de que a perspectiva de marketing apresentada aos alunos atua quase que exclusivamente na análise da relação entre unidades produtoras e unidades consumidoras.

Uma tentativa de aproximação entre marketing e sociedade perpassa a discussão do conceito de responsabilidade social empresarial, que pode estar associado à ideia de responsabilidade legal; ou pode significar um comportamento socialmente responsável no sentido ético; ou pode transmitir a ideia de contribuição social voluntária e associação a uma causa específica (OLIVEIRA; FERREIRA; LIMA, 2015). Muitas organizações, porém, utilizam da responsabilidade social como ferra- 
menta de posicionamento de marketing, agindo por uma perspectiva de micromarketing para gerar resultados positivos em benefício próprio, negligenciando os efeitos em outros agentes. Essa estratégia foi mencionada no grupo de controle.

A visão de marketing está na ponta do iceberg do que as pessoas veem, na parte estratégica é pensado sobre a responsabilidade social e como eu posso evoluir minha imagem, sobre como eu quero que as pessoas me vejam. Ai vai para todo ramo né, a questão de como eu quero que minha imagem impacte a sociedade (GC3).

Apesar deste primeiro comentário confirmar a perspectiva empresarial do grupo, percebe-se uma evolução de pensamento além do contexto empresarial em direção a uma visão mais ampla sobre a relação entre as atividades de marketing e a sociedade. As reflexões permeiam o impacto negativo de alguns produtos, embora ainda esteja implícito o foco da responsabilidade social como uma ferramenta eficaz para promover relações de troca entre unidade produtora e unidade consumidora.

(...) Acho que você pode aliar marketing e sociedade também nesse ponto quando a empresa chega num local ela tem que chegar com um propósito. E esse propósito como já falaram é a responsabilidade social é você entender os objetivos da empresa, missão, visão, e usar em prol da sociedade, das pessoas que vão usar os produtos (GC2).

(...) Nas décadas passadas era muito comum donos de grandes empresas forjarem estudos para favorecer determinados alimentos. Por exemplo, dizer que a gordura é ruim para vender outro produto, ou até mesmo o açúcar. O açúcar não é benéfico para a gente, ele não é proibido, mas o consumo diário não é tão bom. Mas aí o marketing vende o açúcar como produto indispensável e todo mundo consome grandes quantidades dele (GC4).

Por sua vez, um dos participantes comentou sobre a utilização das ferramentas de marketing fora do contexto empresarial:

Eu vejo muito também nessa relação entre marketing e sociedade de querer vender, por exemplo, uma ideia política também. Acho que a gente vê muito a questão do marketing nisso também de querer vender uma ideia para as pessoas (GC6). 
A capacidade de compreender o marketing para além das relações entre empresa e consumidor é uma competência fundamental para o administrador, uma vez que para sua atuação dentro do mercado é necessário entender que os demais agentes também se relacionam entre si, e utilizam ferramentas de marketing para realizar trocas eficientes (FLIGSTEIN; CALDER, 2002). Tamilia e Veilleux (2007) apontam o afastamento entre marketing e sociedade no conteúdo da disciplina de marketing como sendo característica dos cursos de graduação contemporâneos, uma vez que se observou uma crescente concentração do ensino de marketing em temas recorrentes da administração de marketing e do comportamento do consumidor e a tendência à compreensão da sociedade como mero fator externo. A partir do conceito e das ferramentas de marketing desenvolvidas durante a graduação, um dos participantes do grupo de controle reflete sobre quais aspectos de marketing podem se relacionar com a sociedade.

Eu entendo que o marketing influencia muitos aspectos sociais e também culturais. Se eu estou inserido em determinado grupo ou determinada classe, para mim é pré-requisito possuir determinado produto ou utilizar determinado serviço. Eu acho que o marketing é isso, ele consegue encontrar esses espaços e interagir e definir os individuos a partir das coisas que está vendendo. Eu estou vendo do ponto de vista do produto por que na graduação nós não chegamos a ver realmente essa relação entre marketing e sociedade (GC1).

Quando deparados com o mesmo questionamento acerca da relação entre as atividades de marketing e a sociedade, os alunos dos grupos 2 e 3, demonstraram uma perspectiva mais abrangente do que os alunos do grupo de controle, observando que os processos de troca ocorrem para além da relação entre ofertante e demandante. Foi possível observar nos discursos um outro entendimento sobre como a sociedade se configura, sobre as trocas complexas que ocorrem entre ela e os demais agentes de mercado.

Eu acho assim, que essa relação das atividades de marketing, elas mudamo comportamento das pessoas, tipo, nessa questão de vendas e promoção, se o cliente 
for maltratado, gera o comportamento do cliente não ir mais ali. Assim, as atividades de marketing mudam o comportamento das pessoas (GE3).

É possivel aplicar as técnicas de marketing e utilizar para o bem da população também (GE11).

Analisar a relação entre sociedade e marketing social pressupõe que é possível modificar o comportamento das pessoas, e que as ferramentas de marketing podem ser utilizadas neste propósito. Nesse ímpeto, o conhecimento de marketing social possibilitou a compreensão de que as ferramentas de marketing podem ser aplicadas a uma grande variedade de problemas e populações; em diferentes escopos de atuação - global, nacional, regional e até mesmo individual, utilizando uma vasta gama de abordagens que vão além da proposta de vender, sendo utilizadas para promover mudanças sociais sustentáveis (SAUNDERS; BARRINGTON; SRIDHARAN, 2015).

\section{Visão acrítica}

A terceira lacuna no ensino de marketing em cursos de administração apresentada por Sauerbron e Bernadinelli (2017) diz respeito à ausência de uma visão crítica de marketing. Os autores apontam para a necessidade de se complementar o conteúdo da disciplina ensinando uma perspectiva mais ampla a respeito das implicações das atividades de marketing, delineando, consequentemente, uma visão crítica. Os alunos do grupo de controle conseguiram apontar situações nas quais a utilização dos conhecimentos de marketing produziu um resultado benéfico à sociedade.

Acho também esses bancos de sangue, essas campanhas de incentivo à doação, eu acho que trouxe resultados positivos para a sociedade que apelou para a questão também emotiva, a gente vê a necessidade do outro se compadece, pois, pode ser a gente ali no futuro né? E trouxe aquele apelo e muita gente passou a doar mais, pensar mais em doar então acho que trouxe um resultado positivo na sociedade (GC10).

WWF, Greenpeace, Médicos sem fronteiras, fazem campanhas que mexem com o seu pensamento, você se sente a pior pessoa do mundo por não doar um real 
para os caras. Fazem você olhar para dentro, faz você tomar uma atitude, e mesmo que não seja (GC9).

Essa perspectiva demonstra, em determinado nível, uma consciência acerca da utilização do conhecimento de marketing para outras finalidades que não a da venda de produtos ou serviços. Todavia, embora acertada, esta perspectiva continua dentro do espectro reducionista, uma vez que não abrange as demais atividades de marketing além da divulgação. Nos grupos 2 e 3, pode-se perceber um nível de senso crítico em relação aos impactos das atividades de marketing mais ampliado.

Essas atividades do marketing podem ser ferramentas para o bem ou para o mal, se vocêfaz uma campanha de marketing para acabar com sacolas de plásticos ou consumo de produtos prejudiciais, como o cigarro, então o marketing é benéfco, mas se o marketing é usado para o consumismo, para empurrar produtos nas pessoas e elas ficarem endividadas, então é ruim. Então eu acho que ela pode trazer coisas boas e coisas ruins, dependendo de como você usa (GE8).

Eu acho que não adianta você ter aquela formação como administrador, você tem toda aquela noção mercadológica e empresarial, mas se você não colocar em prática o conhecimento com qualidade, você visar apenas o lucro e danificar tudo o que esta ao seu redor, o ambiente, as pessoas, a sociedade. Por isso eu creio que com o marketing é possivel vislumbrar esse mundo de valor, esse mundo melhor (GE5).

Para suprir essa lacuna, é necessário que entendam as ferramentas de marketing como amorais, posto que o impacto na sociedade vai depender unicamente da forma como são usadas. Isso porque, é necessário que os alunos conheçam todas as ferramentas que podem ser aplicadas nas organizações, mas também que eles entendam as implicações e as consequências do marketing na sociedade, uma vez que a organização existe dentro de um sistema de marketing (BERNADINELLI; SAUERBRONN, 2017). Dentro deste contexto, é possível afirmar que esta concepção das atividades de marketing permite ao profissional de administração a expansão do repertório de soluções aplicáveis em situações de trocas complexas, que envolvam vários agentes dentro do mesmo mercado, analisando os impactos causados pelas atividades realizadas. 


\section{DISCUSSÃO DOS RESULTADOS}

O objetivo do estudo foi avaliar as possíveis contribuições do marketing social para a formação dos profissionais de administração, por meio da inserção do tema dentro da grade curricular da disciplina de marketing. Dessa forma, o marketing social serviria para suprir as lacunas de ampliação do conhecimento de marketing presentes nos cursos de administração, identificadas por Bernadinelli e Sauerbronn (2017) e causadas pela perspectiva de ensino focada no micromarketing, relegando conceitos de maior amplitude que são igualmente necessários à formação de profissionais qualificados para compreender e resolver os problemas complexos presentes na sociedade atual (TAMILIA; VEILLEUX, 2007).

Ao analisar os discursos dos alunos, é possível perceber distinções claras no conhecimento apresentado por aqueles que participaram do seminário de marketing social em relação aos que não participaram. Estes últimos, que compuseram neste trabalho o grupo de controle, atestaram as lacunas na formação em marketing dos administradores, uma vez que seu discurso se limitou em grande parte à discussão do marketing enquanto ferramenta empresarial. Embora seja importante para um profissional de administração conhecer as ferramentas do marketing empresarial, é necessária que haja uma reorientação de foco, de modo que as disciplinas de marketing passem a abranger a relação entre o marketing e os problemas sociais, o papel do marketing na modelagem do sistema capitalista e a maneira como o marketing contribui para a estrutura e organização dos mercados, incluindo ainda os aspectos éticos que permeiam a atuação das empresas.

Nesbitt, DeMoranville e Mcnally (2011) explicam que, por focar na resolução de problemas reais, buscando o bem-estar individual e coletivo, é esperado que os próprios alunos ao entrar em contato com a disciplina apresentem mudanças em relação à sua consciência ambiental, suas atitudes e intenções de agir na defesa do ambiente. Além disso, os autores relatam que, ao se engajarem em atividades de marketing social, como as propostas no seminário descrito anteriormente, os alunos demonstram 
uma compreensão mais profunda sobre os problemas que aquela atividade busca solucionar. Dessa forma, detêm maior conhecimento sobre os agentes envolvidos em determinadas situações e das relações complexas de troca que exercem entre si.

Neste sentido, os alunos participantes das atividades propostas no seminário de marketing social demonstraram a compreensão do marketing como uma ciência abrangente que estuda as relações de troca entre os agentes presentes no mercado, bem como uma compreensão de maior amplitude acerca dos agentes que compõem o mercado, e os papéis exercidos por cada um deles. Da mesma forma, foram capazes de realizar uma análise mais profunda acerca da relação entre o marketing e a sociedade, expressando o entendimento de que as atividades de marketing podem ser utilizadas de forma a promover comportamentos benéficos para a sociedade (DIBB, 2014), enquanto o discurso do grupo de controle sobre este tema focou-se na questão da responsabilidade social. Isso demonstra que, embora esses alunos compreendam a necessidade de se tratar dos problemas sociais, sua visão continua restrita ao uso de um discurso "eticamente responsável" para favorecimento do contexto empresarial.

Deste modo, é possível inferir que o ensino do marketing social pode se configurar como uma importante ferramenta na tentativa de suprir as lacunas de conhecimento de marketing apresentadas pelos alunos da graduação em administração. Compreender as implicações do marketing no contexto macroeconômico, analisando as relações entre os agentes que compõem o mercado e como essas relações podem ser transformadas para moldar o ambiente em que estão inseridos fornece subsídios para que o futuro profissional esteja apto a lidar com a complexidade dos mercados competitivos (BRENNAN; LU; HEIDT, 2018; HOLLBROK, 2018).

Os achados desta pesquisa, dada sua natureza experimental e empírica, podem oferecer subsídios para que professores de marketing incluiam o conteúdo de marketing social na grade curricular da disciplina. Ademais, as metodologias ativas se mostraram adequadas para o desenvolvimento de um conteúdo complexo e cheio de camadas de análise. É sugerida a replicação dessa pesquisa em outros níveis de formação e outros contextos 
institucionais, dado o caráter descritivo da metodologia adotada para a realização dessa pesquisa.

Também, pretende-se despertar o interesse de pesquisadores acerca dos aspectos mais sociais do marketing, que embora tenham uma contribuição tão pertinente, ainda não são difundidos de forma ampla no Brasil. Cabe às instituições de ensino promover reflexões coletivas e individuais entre os docentes, para compreender as demandas de mercado e as implicações que emergem a partir da ascensão do debate sobre sustentabilidade e consumo sustentável. Por fim, têm-se a necessidade de os profissionais de educação desenvolverem novos métodos e testarem novas ideias que podem contribuir com o avanço e melhoria da qualidade no ensino superior de administração. 


\section{CONSIDERAÇÕES FINAIS}

O presente trabalho buscou realizar um experimento de inserção do conteúdo de marketing social dentro da disciplina de marketing em um curso de administração, de forma que, por meio de análise posterior, pudessem ser identificadas as suas contribuições para melhoria na formação dos alunos. Com isso, a coleta dos dados se deu por meio da realização de grupos focais distintos, sendo dois deles formados por alunos que participaram do experimento, e outro, denominado de grupo de controle, por alunos que vivenciaram a disciplina de marketing sem a inserção dos conteúdos de marketing social. Dessa forma, a análise buscou identificar, mediante dos discursos proferidos pelos alunos, a existência de deficiências no ensino da instituição, e, em caso positivo, se o conteúdo inserido na disciplina contribuiu de alguma forma para supri-las.

Os alunos que participaram do seminário de marketing social apresentaram resultados diferenciados, de modo que nos grupos focais, demonstraram conhecimentos mais amplos quando comparados com seus pares do grupo de controle, no que se refere à natureza e o escopo das atividades de marketing bem como a composição e os agentes dos mercados. Portanto, é possível afirmar que o objetivo geral do artigo foi alcançado, uma vez que foi evidenciada a viabilidade do ensino do marketing social como forma de promover a qualidade do aprendizado dos alunos de administração, no que tange aos conhecimentos de marketing, sendo esta a principal contribuição do presente artigo.

Entre as limitações desta pesquisa, destaca-se a realização do experimento com uma amostragem relativamente pequena frente ao número expressivo de graduandos em administração, como também o fato da necessidade de isolar as demais variáveis que podem interferir no processo de aprendizagem. Como sugestão de trabalhos futuros, indica-se que sejam realizadas novas pesquisas que busquem expandir a discussão de marketing, tanto em termos teóricos quanto empíricos, de forma a compreender e analisar a inserção de novos conteúdos nas disciplinas de marketing e como podem contribuir para a melhoria da performance profissional dos alunos e dos cursos de Administração no Brasil. 


\section{REFERÊNCIAS}

BARBOZA, S. I. S. Sistema de Marketing Alimentar: Uma análise da consideração ética do produto de origem animal. 2014. Tese (Doutorado em Administração) - Programa de Pós-graduação em Administração. Universidade Federal da Paraíba, Paraíba.

BARDIN, L. Análise de conteúdo. São Paulo: Edições 70; 2011

BERNADINELLI, R. P.; SAUERBRONN, J. F. Contribuições do Macromarketing para a formação de administradores: podemos melhorar o ensino de marketing em cursos de administração? Administração: Ensino e Pesquisa, v. 18, n. 3, p. 558-593, 2017. doi. org/10.13058/raep.2017.v18n3.628

BOAVENTURA, P. S. M.; SOUZA, L. L. F.; GERHARD, F.; BRITO, E. P. Z. Desafios na formação de profissionais em administração no Brasil. Administração: Ensino e Pesquisa. Rio de Janeiro, v.19, n. 1, p. 01-31, 2018. doi.org/10.13058/raep.2018.v19n1.775

BOSCHI, M. R.; BARROS, D. F.; SAUERBRONN, J. F. R. A introdução da disciplina de marketing no Brasil: "uma linguagem comum que nos une". Farol: revista de estudos organizacionais e sociedade, v. 3, n. 8, p. 857-924, 2016. doi.org/10.25113/farol.v3i8.3872

BRENNAN, L.; LU, V. N.; HEIDT, T. Transforming Marketing Education: Historical, comtemporany and future perspectives. Australasian Journal of Marketing, v. 26, n. 2, p. 65-69, 2018. doi.org/10.1016/j.ausmj.2018.05.011

BRENNAN, L.; PARKER, L. Beyond behaviour change: social marketing and social change. Journal of Social Marketing, v. 4, n. 3, p. 261-282, 2014. doi.org/10.1108/JSOCM-08-2014-0052

CARVALHO, H. C.; MAZZON, J. A. A better life is possible: the ultimate purpose of social marketing. Journal of Social Marketing, v. 5, n. 2, pp. 169-186, 2015. doi.org/10.1108/ JSOCM-05-2014-0029

COELHO, R. C. Estado, governo e mercado. 3 ed. Florianópolis: Departamento de Ciências da Administração/UFSC, 2014.

COSTA, C. R. F. e VIEIRA F. G. D. Marketing no Brasil: pensamento e ação sob uma perspectiva historiográfica. Caderno de administração. v. 15, N.2, p. 39-48, jul/ dez, 2007.

DA EDUCAÇÃO SUPERIOR, INEP Censo. Notas Estatísticas. 2016. Ministério da Educação, 2018.

FLIGSTEIN, N.; CALDER, R. Architecture of Markets. In: SCOTT, R. A., KOSSLYN, S. $\mathrm{M}$ (org.). Emerging Trends in the social and behavioral sciences. New Jersey: Wiley, 2015. doi. org/10.1002/9781118900772.etrds0014

FRENCH, J.; BENNETT, R. R.; MULCAHY, R. Travelling alone or travelling far? Meso-level value co-creation by social marketing and for profit organisations. Journal of Social Marketing, v. 7, n. 3, p. 280-296, 2017. doi.org/10.1108/JSOCM-12-2016-0088 
GORDON, R.; GURRIERI, L. Towards a Reflexive Turn: Social Marketing Assemblages. Journal of Social Marketing, v. 4, n. 3, p. 261-78, 2014. doi.org/10.1108/JSOCM-02-2014-0015

HAMBY, A.; PIERCE, M., BRINGBERG, D. Solving Complex Problems: Enduring Solutions through Social Entrepreneurship, Community Action, and Social Marketing. Journal of Macromarketing, v. 37, n. 4, p. 369-380, 2017. doi.org/10.1177/2F0276146716663797

HILL, R. P.; MARTIN, K. D. Broadening the paradigma of marketing as Exchange: a public policy and marketing perspective. Journal of Public Policy \& Marketing, v. 33, n.1, p. 17-33, 2014. doi.org/10.1509/jppm.13.023

HOLLBROK, M. B. A subjective personal introspective essay on the evolution of business schools, the fate of marketing education, and aspirations toward a great society. Australasian Marketing Journal, v. 26, n. 2, p. 70-78, 2018. doi.org/10.1016/j.ausmj.2018.05.010

HUNT, S. D.; BURNET, J. J. The macromarketing/micromarketing dicotomy: a taxonomical model. Journal of Marketing, v. 46, n. 3 p. 11-26, 1983.

KENNEDY, A.; KEMPER, J. A.; PARSONS, A. G. Upstream Social Marketing Strategy. Journal of Macromarketing, v. 8, n. 3, p. 258-279, 2018. doi.org/10.1108/JSOCM-03-2017-0016

KOTLER, P.; ARMSTRONG, G. Princípios de Marketing. 15 ed. São Paulo: Pearson Brasil, 2014.

KOTLER, P. A Framework for Marketing Management, Upper Saddle River NJ: Pearson/ Prentice Hall, 2013.

KOTLER, P.; ZALTMAN, G. Social marketing: An approach to planned social change. Journal of Marketing, v. 35, n. 3, p. 3-12, 1971.

LEE, N.; GREENLEY, G.E, The theory-practice divide: thoughts from the Editors and Senior Advisory Board of EJM. European Journal of Marketing, v.44, n.1-2, p.5-20, 2010.

LOURENÇO, C. D. S.; TONELLI, D. F.; MAFRA, F. L. N. Reconciliação entre o econômico e o social: um desafio para o ensino de Administração. In: ENCONTRO DE ENSINO E PESQUISA EM ADMINISTRAÇÃO E CONTABILIDADE DA ANPAD. 2. Curitiba. Anais..., Curitiba: ANPAD, 2009.

MAIO, G. R. et al. Social Psychological Factors in Lifestyle Change and Their Relevance to Policy. Social Issues and Policy Review, v. 1, n. 1, p. 99-137, 2007. doi.org/10.1111/ j.1751-2409.2007.00005.x

MARTINS, C. B. Surgimento e expansão dos cursos de administração no Brasil (19521983). Ciência e Cultura, v. 41, n. 7, p. 663-676, jul. 1989.

MORAES, T. A.; LACERDA, J. O. S. Não Zere a Quilometragem, meu Jovem! Marketing Social para Educação no Trânsito. Métodos e Pesquisa em Administração, v. 1, n. 1, p. 76-82, 2016. 
MULLER, S. H.; SCHUSTER, H. A.; ZONATTO, V. C. S. Oportunidades de melhoria no ensino de disciplinas que abrangem conteúdos de Custos: uma análise com base na percepção de discentes. Administração: Ensino e Pesquisa, v. 18, n. 2, p. 301-344, 2017. doi. org/10.13058/raep.2017.v18n2.535

NESBITT, J. M.; DEMORANVILLE, C. W.; MCNALLY, D. A strategy for advancing social marketing: Social marketing projects in introductory marketing courses. Journal of Social Marketing, Vol. 2, n.1, p.52-69, 2012.

NIBLETT, G. R. Stretching the limits of social marketing partnerships, upstream and downstream: Setting the context for the 10th Innovations in Social Marketing Conference. Social Marketing Quarterly, v. 11, p. 9-15, 2015. doi.or$\mathrm{g} / 10.1080 / 2 \mathrm{~F} 15245000500308898$

OLIVEIRA, A. L.; LOURENÇO, C. D. S.; CASTRO, C. C. Ensino de administração nos EUA e no Brasil: uma análise histórica. Pretexto, v. 16, n. 1, p. 11-22, 2015. doi. org/10.21714/pretexto.v16i1.1830

OLIVEIRA, M.; FERREIRA, M. R.; LIMA, V. Responsabilidade social corporativa: conceito, instrumentos de gestão e normas. Revista Brasileira de Administração Científica, v. 6, n. 2, p. 161-172, 2015. doi.org/10.6008/SPC2179-684X.2015.002.0011

RADFORD, Scott K.; HUNT, David M.; ANDRUS, Deborah. Experiential Learning Projects: A Pedagogical Path to Macromarketing Education. Journal of Macromarketing, v. 35, n. 4, p. 466-472, 2015. doi.org/10.1177/2F0276146715573834

RODRIGUES, E. R.; MATIAS, A. B. Ensino em administração: proposta do conteúdo programático de finanças. Administração: Ensino e Pesquisa, v. 17, n. 2, p. 245-274, 2016. doi.org/10.13058/ raep.2016.v17n2.403

ROSSI, G. B.; SERRALVO, F. A.; JOÃO, B. N. Análise de Conteúdo. Revista Brasileira de Marketing, v. 13, n. 4, p. 39-48, 2014.

SAUERBRONN, F. F. Trajetória, desafios e tendências no ensino superior de administração e administração pública no Brasil: uma breve contribuição. RAP: Revista de Administração Pública, Edição Especial Comemorativa, p. 149-170, 2007.

SAUNDERS, S. G.; BARRINGTON, D. J.; SRIDHARAN, S. Redefining social marketing: beyond behavioural change. Journal of Social Marketing, v. 5, n. 2, pp.160-168, 2015. https: / / doi.org/10.1108/JSOCM-03-2014-0021

SCHIMTZ, L. C.; ALPERSTEDT, G. D.; BELLEN, H. M. V.; SCHIMITZ, J. L. Limitações e dificuldades na utilização da abordagem experiencial no ensino de gerenciamento de projetos em um curso de graduação em administração. Administração: Ensino e Pesquisa, v. 16, n. 3, p. 537-569, 2015. dx.doi.org/10.13058/raep.2015.v16n3.283

TAMILIA. R. D.; VEILLEUX. S. Teaching Macromarketing at the Undergraduate Level: A Needed Reality in the 21ST Century. ASAC, Otawa. v. 28, n. 1, p. 39-57. 2007. 
TEKLEHAIMANOT, M. L.; et al. Moving Toward New Horizons for Marketing Education: Designing a Marketing Training for the Poor in Developing and Emerging Markets. Journal of Marketing Education, v. 39, n. 1, p. 47-60, 2017. https: / / doi.or$\mathrm{g} / 10.1177 / 2 \mathrm{~F} 0273475316688318$

URIAS, G. M. C.; AZEREDO, L. A. S. Metodologias ativas nas aulas de administração financeira: alternativa ao método tradicional de ensino para o despertar da motivação intrínseca e o desenvolvimento da autonomia. Administração: Ensino e Pesquisa, v. 18, n. 1, p. 39-67, 2017. doi.org/10.13058/raep.2017.v18n1.473

VASCONCELOS, M. D.; COSTA, F. J.; CARVALHO, D. T. Educação em Marketing: Visões e Práticas de Domesticação no Contexto Nordestino. REUNIR - Revista de Administração, Ciências Contábeis e Sustentabilidade, v. 6, n. 1, p. 107-117, 2016. doi.org/10.18696/ reunir.v6i1.427

WOOD, M. Midstream social marketing and the co-creation of public services. Journal of Social Marketing, v. 6, n. 3, p. 277-293, 2016. doi.org/10.1108/JSOCM-05-2015-0025 
DA SILVA

\section{DADOS DOS AUTORES}

\section{STEPHANIE INGRID SOUZA BARBOZA stephanieisb@gmail.com}

Doutora em Administração pela PPGA-UFPB

Instituição de vinculação: Departamento de Ciências Sociais Aplicadas - Campus III /

Programa de Pós-Graduação em Gestão Pública e Cooperação Internacional - Universi-

dade Federal da Paraíba

Bananeiras e João Pessoa/Paraíba - Brasil

Áreas de interesse em pesquisa: Marketing no interesse público.

Universidade Campus Universitário III - R. João Pessoa, $s / n \quad$ Cidade Universitária Bananeiras $/ \mathrm{PB} \quad 58220-000$

\section{WESLEY FERREIRA DA SILVA wezley.ferreirasilva@gmail.com}

Bacharel em Administração pela UFPB

Instituição de vinculação: Universidade Federal da Paraíba

Guarabira/Paraíba - Brasil

Áreas de interesse em pesquisa: Marketing Social, Educação em Marketing, Ensino em Administração. 